\title{
Ganglion Cyst of the Distal Tibia: A case report
}

\author{
by Ali Abadi, DPM ${ }^{1 凶}$, Jennifer Berlin, DPM ${ }^{2}$, Warren Mangel, DPM ${ }^{3}$
}

The Foot and Ankle Online Journal 2 (11): 2

A 42 year-old female with persistent pain and numbness to the left foot and ankle is presented. Magnetic resonance imaging shows a ganglion cyst communicating to a cystic region within the tibia. The cyst is surgically excised and the tibia is curettaged and packed with cancellous bone chips. The ganglion is confirmed to be communicating with the left distal tibia bone. We present an unusual case of a ganglion cyst arising from bone.

Key words: Ganglion cyst, benign tumor, distal tibia.

Accepted: October, 2009

Published: November, 2009

This is an Open Access article distributed under the terms of the Creative Commons Attribution License. It permits unrestricted use, distribution, and reproduction in any medium, provided the original work is properly cited. @The Foot and Ankle Online Journal (www.faoj.org)

$\mathrm{T}$ The term ganglion was first used by Hippocrates to designate a knot of tissue filled with "mucoid flesh". It is a cystic swelling, $1-3$ $\mathrm{cm}$ in diameter, found typically in close proximity of joints and tendon sheath. The most common sites are the dorsal and volar aspect of the wrist, the dorsum of the foot, and around the ankle and the knee. ${ }^{1}$ Ganglion cysts are well demarcated and movable within the surrounding tissue and are often loosely attached to a tendon sheath or the capsule of a joint. The dense fibrous capsule encloses the cyst which contains a viscid, jelly-like fluid rich in hyaluronic acid and other acid mucopolasaccharides. ${ }^{2}$

Address Correspondence to: Dr ALI Abadi, West Jersey Virtua Hospital, New Jersey. 101 Carnie Blvd., Voorhees, NJ 08043

E-mail : aa78@georgetown.edu

${ }^{1}$ PGY-1, Virtua Hospital, 101 Carnie Blvd., Voorhees, NJ 08043.

${ }^{2}$ Attending, Virtua Hospital, 101 Carnie Blvd., Voorhees, NJ 08043.

${ }^{3}$ Chief of Podiatry Surgery, Virtua Hospital, 101 Carnie Blvd., Voorhees, NJ 08043 .

\section{Case Report}

A 42 years-old female patient presents with severe pain and numbness to the left foot and ankle. The patient presents to the doctor's office complaining of intermittent pain and numbness of the left toes. The patient relates to mild pain while ambulating and going up the stairs. There is no history of trauma. Radiographs are negative for stress fracture. Conservative treatment is initially attempted to relive symptoms. This consisted of oral anti inflammatory medication and ankle bracing for stabilization. This was found to be ineffective. The pain is now intermittent and not affecting quality of life.

Magnetic Resonance Image (MRI) of the foot and ankle reveals a ganglion measuring $3 \mathrm{~cm}$ above ankle joint. This area was asymptomatic on physical examination. The patient opted to monitor its progression. Two years later, the patient now experiences constant numbness of the left foot and toes as well as painful swelling along the posterolateral aspect of the leg. Surgery is discussed and planned for removal of the ganglion cyst. 


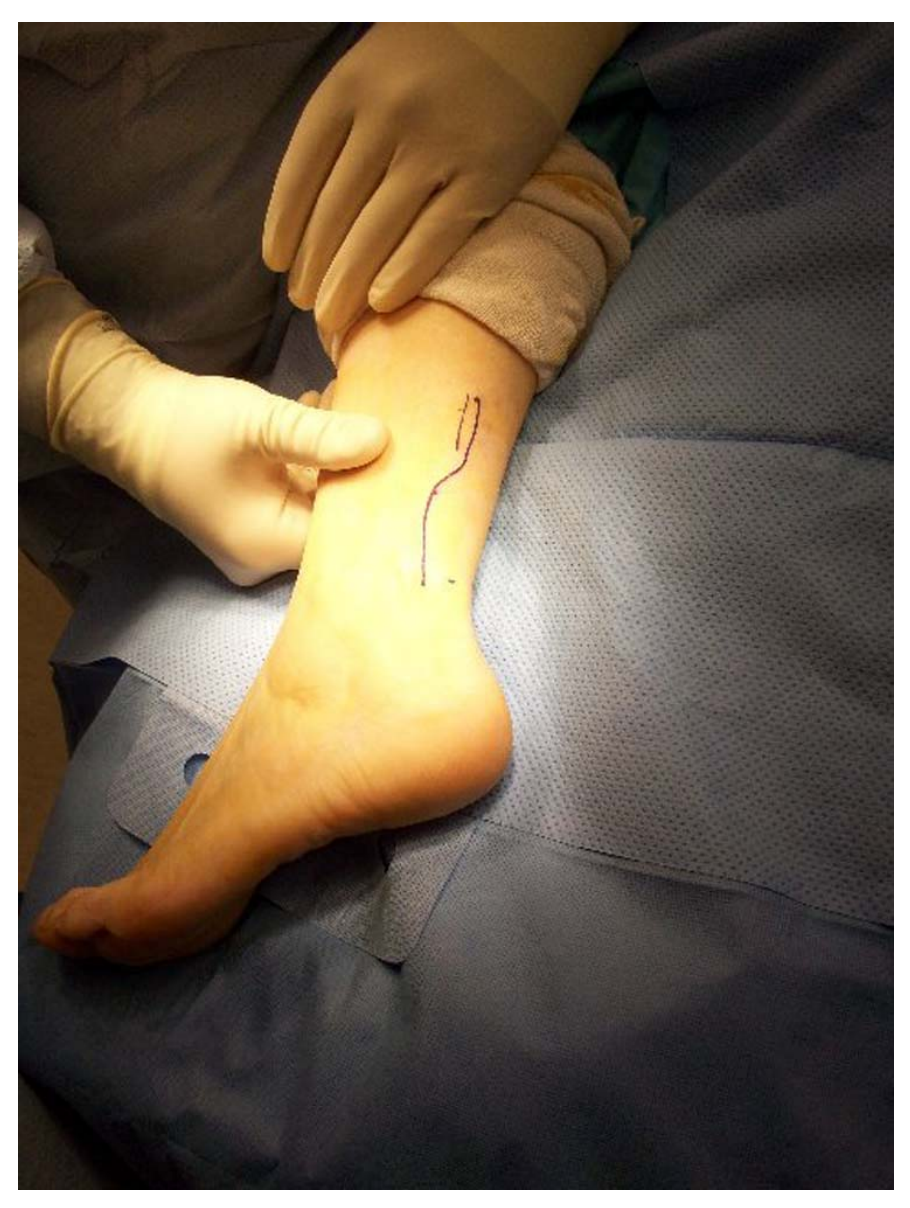

Figure 1 Left leg with surgical mark.

There is now point tenderness and pain on palpation around the posterolateral aspect of the left ankle. Numbness is affecting the toes. (Fig. 1) Plain radiographs reveal a moderate increase in soft tissue swelling around the lateral malleolus. (Fig. 2) Radiographic studies are negative for stress fracture or other obvious osseous abnormalities.

Laboratory examination included corpuscular blood count with differential count, white blood cell count, rheumatoid factor, C-reactive protein, erythrocyte sedimentation rate, and serum uric acid are all unremarkable. Electromyography result is negative for sciatica.

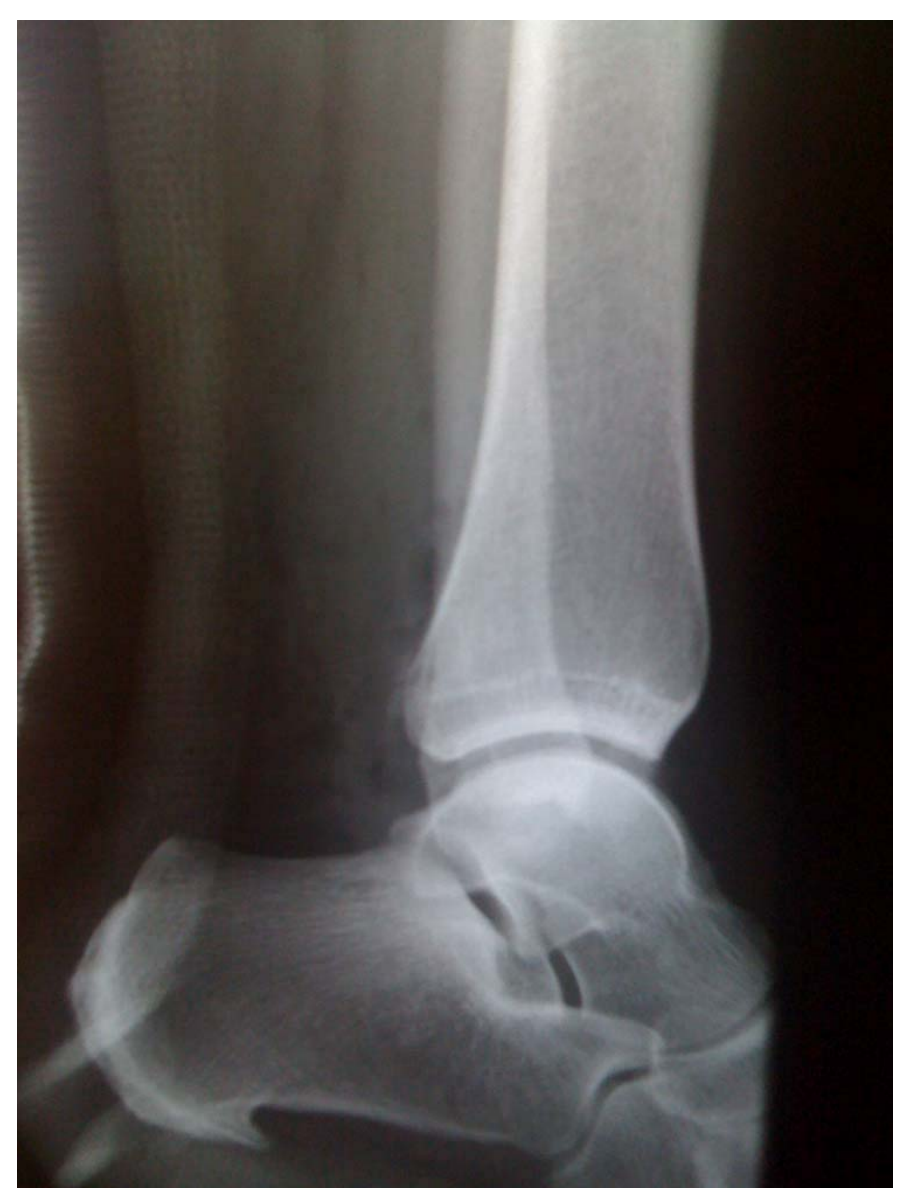

Figure 2 Lateral radiograph, left foot and ankle.

Magnetic resonance imaging of the ankle reveals a cystic lesion of $3 \mathrm{~cm} \times 1.5 \mathrm{~cm}$ in diameter with tibial bone erosion. Sagittal views showing a decreased signal intensity in T1 (Fig. 3A) and a well defined homogeneous bright signal in T2 (Fig. 3B) extending to the posterolateral aspect of the distal tibia. ${ }^{3}$

Surgical excision was performed. After inflating the thigh tourniquet, the ganglion cyst is excised through a $7 \mathrm{~cm}$ posterolateral incision. (Fig. 1) The mass is separated from the surrounding Flexor hallucis longus muscle and tissues. There is a well-defined capsule. The cystic mass is $3 \mathrm{~cm} \times 1.5 \mathrm{~cm}$ and penetrating the tibial bone. (Figs. 4A - D) The bone defect is evacuated with a bone currette and packed with cancellous bone chips. The tibial bone defect is about $1 \mathrm{~cm}$. deep.(Figs. 5A and B) 


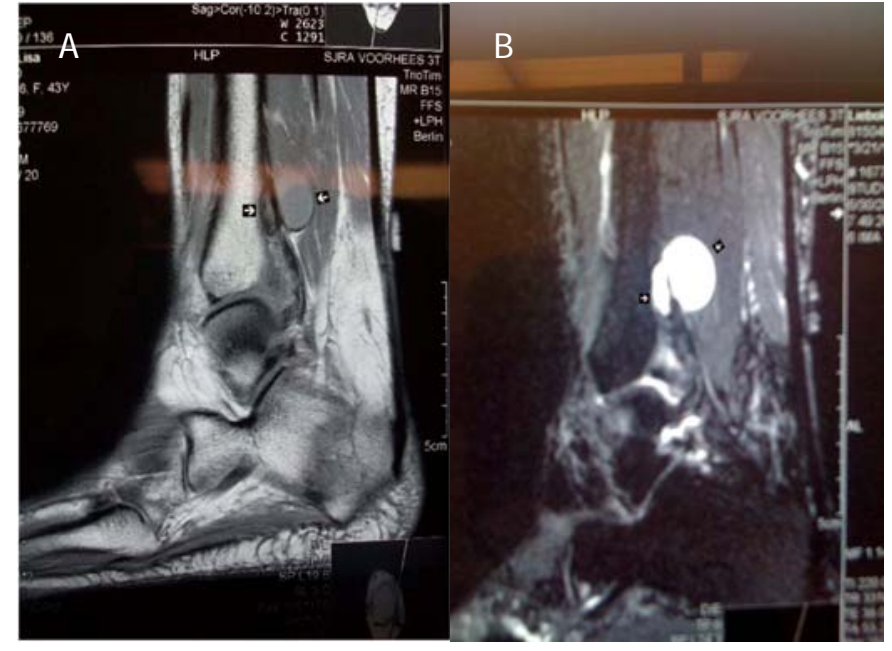

Figures 3A and B Sagittal view MRI (A) and cyst on T2 image showing cyst origin in bone. (B)

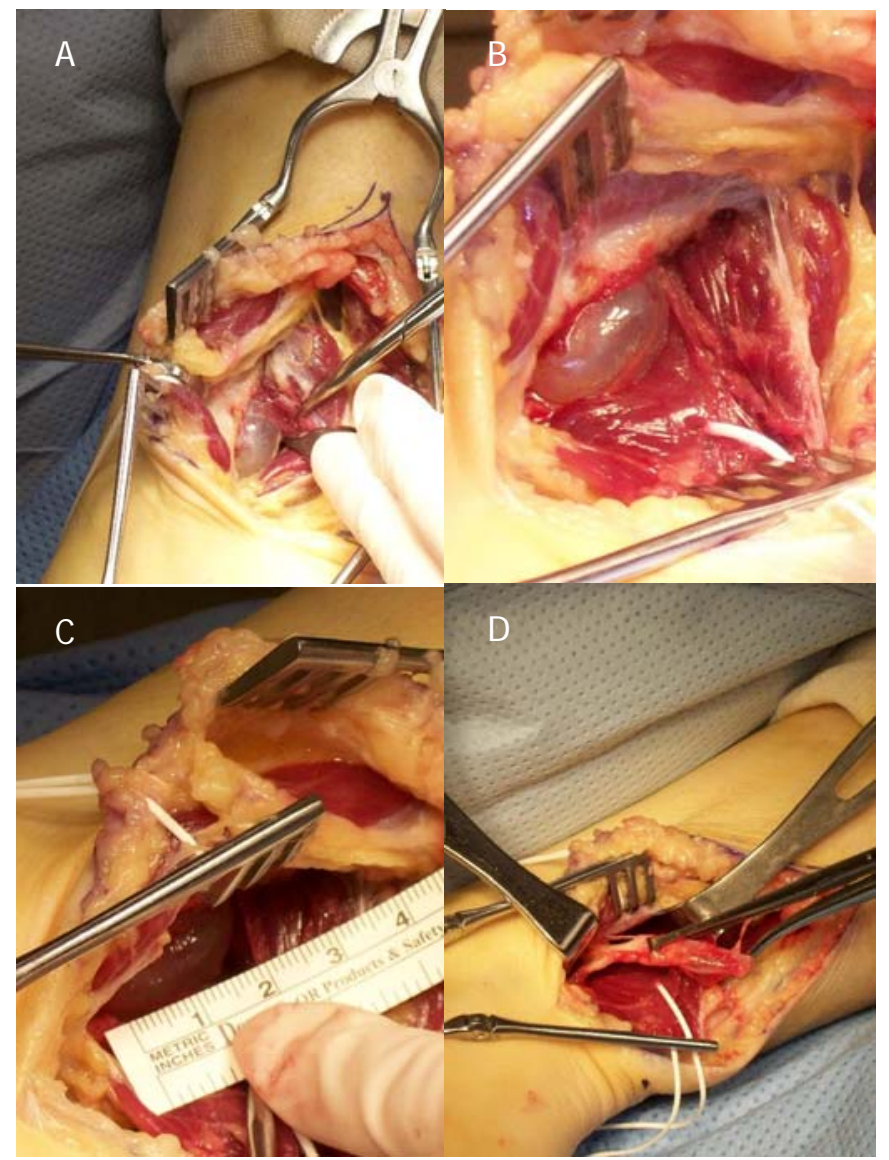

Figures 4A - D Intra-operative photograph showing the ganglion cyst intact. (A) A close-up of the cyst as it presents. (B) The ganglion measures $3 \times 1.5$ centimeters. (C) Intraoperative photo showing cyst dissection. (D)

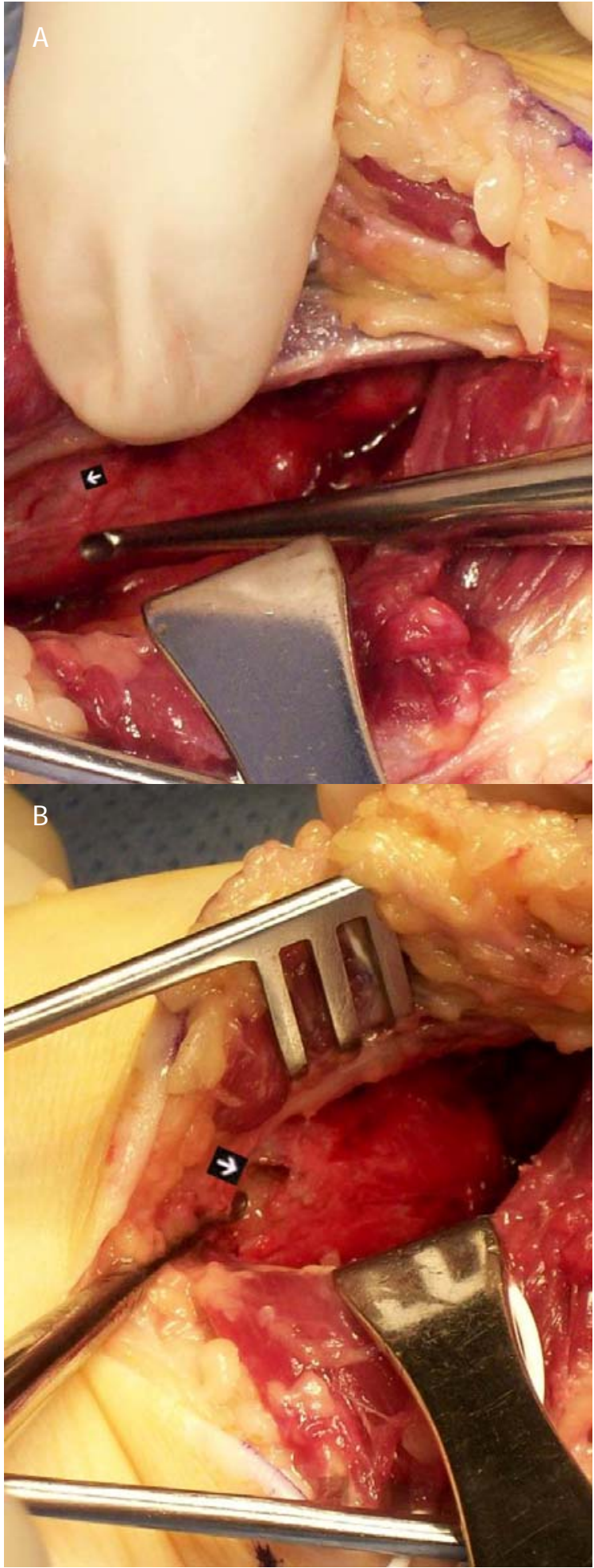

Figures 5A and $\mathbf{B}$ Intra-operative photograph showing tibial erosion. (A) When evacuated, there is an exposed cavity within the tibia that reveals the cyst origin. (B)

(C) The Foot and Ankle Online Journal, 2009 
The pathology report is consistent with the diagnosis of ganglion. The cyst measured $3.5 \times 3 \mathrm{~cm}$ with a wall of $0.1 \mathrm{~cm}$ thick that was composed of collagenous connective tissue. It presented along with several islands of mucinous material. No epithelial lining was noted. There was no reported evidence of neoplasm, inflammation or granuloma.

Postoperatively, the patient is pain-free and shows normal strength and sensation in the left foot and ankle. No recurrence has been noted up until the writing of this report.

\section{Discussion}

The ganglion cyst is the most common soft tissue mass found in the foot and ankle. ${ }^{4}$ It is also a common occurrence in hand or wrist. A ganglion is a well-circumscribed, soft, and fluid-filled cystic mass that is frequently freely movable in the subcutaneous tissues and most often is found on the dorsum of the foot. $^{4}$ The exact etiology is unknown; however, traumatic, degenerative or inflammatory process in adjacent joints has been suggested as possible etiological factors. ${ }^{5}$

MRI is the modality of choice in the assessment of soft tissue tumors. On MRI, ganglion cysts demonstrate low intensity on T1 and high signal intensity on T2 weighted images.

Although $75 \%$ of all biopsy proved soft tissue masses of the foot and ankle are benign, ${ }^{6,7}$ ganglion cysts should be differentiated from other tumors such as lipoma, hemangioma, infection and malignant tumors, such as malignant fibrous histiocytoma. ${ }^{8}$

\section{References}

1. Carp L, Stout AP: A study of ganglion with special reference to treatment. Surgery, Gynecology and Obstetrics 47: 460 - 468, 1928.

2. Soren A: Pathogenesis and treatment of ganglion. Clin Orthop Relat Res 48: 173 - 179, 1966.

3. Crim JR, Cracchiolo A, Hall R: Imaging of the foot and ankle. Imaging of the Foot and Ankle. 244. London: Martin Dunitz Ltd, 1996.

4. Hattrup SJ, Amadio PC, Sim FH, Lombardi RM: Metastatic tumors of the foot and ankle. Foot Ankle 8: 243-247, 1988.

5. Steiner E, Steinbachh LS, Schnarkowski P: Ganglia and cyst around joints. Radiol Clin North Am 34: 395 - 425, 1996.

6. Llauger J, Palmer J, Monill JM, Franquet T, Bague S, Roson $\mathrm{N}$ : MR imaging of benign soft tissue masses of the foot and ankle. Radiographics 1481 - 1498, 1998.

7. Pontius J, Good J, Maxian S: Ganglions of the foot and ankle: A retrospective analysis of 63 procedures J Am Podiatr Assoc 89: 163 - 168, 1999.

8. Banks AS, Downey MS, Martin DE, Miller SJ, McGlamry ED: McGlamry's Comprehensive Textbook of Foot and Ankle Surgery. Lippincott Williams and Wilkins; 3rd Revised edition, 1354 1366, 2001. 